\title{
Fostering Critical Thinking in First-Year Students through Information Literacy Instruction
}

\author{
Mandi Goodsett and Hanna Schmillen
}

As students encounter high volumes of misinformation in online environments, cultivating critical thinking is an important goal of information literacy instruction, especially for first-year college students, who are just beginning to develop cognitive habits in their early years of postsecondary schooling. However, this study demonstrates that the relationship between critical thinking and information literacy is not obvious, and relatively little has been recently studied regarding how academic librarians incorporate critical thinking into their library instruction. Through a series of in-depth interviews, the researchers sought to understand how academic librarians who primarily instruct first-year college students conceive of, teach, and assess critical thinking skills in relation to information literacy.

\section{Introduction}

Critical thinking, while often used as a buzzword, is clearly relevant to the mission and expertise of librarians who teach, as well as the ACRL Framework for Information Literacy. ${ }^{1}$ Especially now, as students encounter misinformation, as well as radically conflicting viewpoints in the media and among politicians and leaders, librarians are in a prime position to develop the skills necessary to empower students to navigate this confusing information environment. First-year college students are a particularly important population to target for developing critical thinking skills, as they are spending their first years of postsecondary schooling building foundational skills and cognitive habits. ${ }^{2}$ However, it is not clear from the literature how comfortable academic librarians are with teaching critical thinking or what their attitude toward the concept may be. This study seeks to explore how academic librarians who primarily teach first-year students conceive of, teach, and assess critical thinking skills in relation to information literacy instruction.

\section{Objectives}

- To explore the attitudes of librarians who teach first-year students toward teaching critical thinking

- To define critical thinking and its relationship to information literacy as understood by librarians who teach first-year students

\footnotetext{
*Mandi Goodsett is the Performing Arts E Humanities Librarian, as well as the OER and Copyright Advisor, at Cleveland State University; email: a.goodsett@csuohio.edu. Hanna Schmillen is Head of Subject Liaisons Services and Health Sciences Librarian at Ohio University; email: schmille@ohio.edu. (C2022 Mandi Goodsett and Hanna Schmillen, Attribution-NonCommercial (https://creativecommons.org/licenses/by-nc/4.0/) CC BY-NC.
} 
- To determine how much, and in what ways, academic librarians incorporate critical thinking instruction and assessment methods into their information literacy first-year student instruction

To achieve the study objectives, the researchers conducted 21 interviews with librarians who teach first-year students on a regular basis, analyzed their responses, and used a qualitative framework to identify themes related to the study objectives.

\section{Literature Review}

While critical thinking theory and instruction have been a subject of study for decades, the relationship between critical thinking and information literacy has not been extensively explored in the library literature. With the development and increasing use of the ACRL Framework for Information Literacy, which emphasizes higher-order thinking concepts, it is clear that academic librarians may have a significant role to play in helping to reinforce and/ or develop the critical thinking skills of college students. This is especially true of information literacy instruction for first-year students, who are still developing cognitively and building a foundation upon which to cultivate their research skills.

There are a great many definitions of critical thinking in the literature. ${ }^{3}$ For the purposes of this study, critical thinking is defined as "reason- and evidence-based skepticism that habitually challenges both internally- and externally-generated ideas as a means to guide decision-making, problem-solving, and action." ${ }^{4}$ Internally generated ideas are those that an individual has, while externally generated ideas are those that an individual encounters from outside sources. The dual nature of this definition emphasizes the skills of evaluation and analysis, as well as the habits of open-mindedness and metacognition, which result in a decision or action.

Much has been written about critical thinking in the fields of psychology, philosophy, and education. In the realm of philosophy, the focus is on the ideal critical thinker, and philosophers like Richard Paul, ${ }^{5}$ Robert Ennis, ${ }^{6}$ Peter Facione, ${ }^{7}$ Gerald Nosich, ${ }^{8}$ and John McPeck ${ }^{9}$ have contributed greatly to the understanding of what critical thinking is. Psychologists, such as Deanna Kuhn, ${ }^{10}$ Diane Halpern, ${ }^{11}$ and Patricia King and Karen Kitchener, ${ }^{12}$ tend to theorize about and study the critical thinking behaviors that humans do (and do not) demonstrate. Along with educators, psychologists also research cognitive development and how maturation reflects changes in critical thinking levels, ${ }^{13}$ an important consideration when examining critical thinking in first-year college students. The work of both philosophers and psychologists have been applied to the field of education to reveal a number of strategies for encouraging critical thinking. These strategies include, but are not limited to, discussion, inquiry-based learning, the use of real-world problems, the use of graphic organizers, problem-based learning, reflection, and practice of critical thinking skills. ${ }^{14}$

Peak interest in understanding and integrating critical thinking into the curriculum came in the late 1980s, ${ }^{15}$ and librarianship's relationship with critical thinking was changing at this time as well. In the 1980s and 1990s, librarians began to see their roles increasingly encompass research instruction. Some scholars at the time expressed concern that these librarians conceived of "bibliographic instruction" as merely helping students use library tools to search for information. ${ }^{16}$ This attitude was reflected in the "back to basics" movement of library instruction, which urged librarians to limit their instruction strictly to teaching research tool use. ${ }^{17}$ Librarians who resisted this limitation called on their colleagues to move beyond these 
simple "point-and-click" skills and to also cultivate critical thinking skills. With the adoption of the ACRL Framework for Information Literacy in 2016, the academic librarian community accepted a guiding document for information literacy instruction that focuses almost exclusively on higher-order thinking skills. While the Framework does not specifically mention critical thinking, the document makes clear that the librarian community has come a long way from merely emphasizing the "basics." Support for higher-order thinking skills are also clearly present in contemporary information literacy instruction models, such as metaliteracy and the CILIP (Chartered Institute of Library and Information Professionals) information literacy definition developed in $2018 .^{18}$

While support for teaching critical thinking skills in library instruction has grown, the relationship between information literacy and critical thinking remains unclear. Some librarians view information literacy as consisting of the concrete skills of locating and using information, which then can be applied using critical thinking skills. ${ }^{19}$ Others see the two sets of skills as distinct, but with the capacity to be "meshed" during library instruction. ${ }^{20}$ Still others see correlations between critical thinking and information literacy but view critical thinking as internal mental processes and information literacy as the observable behaviors to which critical thinking gives rise. ${ }^{21}$ None of these scholars suggest that information literacy and critical thinking overlap significantly, nor imply that the concepts of information literacy and critical thinking are the same.

In the time since the "back to basics" movement, the focus of library instruction has shifted considerably toward a focus on higher-order thinking skills, as demonstrated by the ACRL Framework. However, challenges to teaching critical thinking in information literacy instruction remain, including the librarian instructor's lack of control over the instruction environment/parameters, lack of adequate time in the session, and insufficient formal training in instruction. ${ }^{22}$ These challenges can be compounded for first-year student instruction, as librarian interaction with students may be chiefly through general education courses that are large, standardized, and packed with content. First-year students may also have inconsistent prior experiences learning critical thinking skills, making it difficult to teach relevant critical thinking skills to all students in a class.

Despite these difficulties, information literacy instruction is a prime opportunity for librarians to develop critical thinking skills in first-year students. Higher educational institutions generally agree that critical thinking is a key learning outcome for students and an important indicator of success. ${ }^{23}$ The focus on critical thinking instruction for first-year students in this study was deliberate for several reasons. First, the positive impact of critical thinking instruction/courses to first-year students has been demonstrated in higher education scholarship. ${ }^{24}$ The value of critical thinking instruction early in a student's higher education career helps them to understand what critical thinking is, ${ }^{25}$ increases their metacognitive skills, ${ }^{26}$ and ensures a scaffolded and equitable approach to these important concepts.

\section{Methods}

In this study, 21 academic librarians across the country who teach first-year students were recruited through an open call for volunteers on a variety of listservs. For qualitative research, a sample of 21 is generally considered sufficient to be representative. The volunteer participants were then interviewed following a revised version of the protocol developed by the California Commission on Teacher Credentialing. ${ }^{27}$ This protocol was used by the Commission in 1997 
to determine the extent to which primary and secondary school teachers were prepared to teach critical thinking skills. Despite focusing on teachers of younger students, the Commission's study had very similar goals to this one and the protocol was, therefore, with some modification, an appropriate tool to use. Modifications included eliminating questions only relevant to full-time instructors and changing some questions to better reflect how librarians design and deliver instruction. Prior to being interviewed, participants were given the protocol and agreed to participate in the IRB-approved study. All interviews were completed over the phone and were recorded using the secure ACR phone application..$^{28}$ The questions attempted to discover how first-year instruction librarians conceive of and use critical thinking in their teaching. Additionally, the researchers asked questions about participants' teaching experience, education, and other demographic information (see full interview protocol in appendix A).

The interviews were transcribed from the audio recordings using the Google Docs speechto-text feature, and participant names were replaced with pseudonyms. After an initial review of the transcripts, the researchers separately applied preliminary codes relevant to answering the research questions of the study (no software was used). The researchers then compared their independently developed codes to establish a master list of finalized codes (see appendix $B$ for the final codebook).

After deliberation, the researchers chose to use a percent agreement calculation for interrater reliability rather than a Cohen's kappa or Krippendorf's chi because these latter methods are meant to work with quantitative data and account for chance agreement. With more than 20 codes, it is very unlikely that any agreement on the part of the coders was by chance. In addition, the qualitative nature of this research makes exact agreement less important than the understanding of the ideas and meaning presented by the participants. ${ }^{29}$ The nature of the data also guided the researchers' decision to discuss coding before calculating interrater reliability. The best methodology for the context and goals was to carefully ground the code manual to represent the participants' ideas and experiences, to have significant discussion about the application of codes, and to ensure a straightforward comparison of coding between the researchers.

To determine interrater reliability, the researchers split the transcripts of 20 percent of the participants (four transcripts) into "meaning units," or smaller textual units that could each be assigned a single code. A meaning unit could be a paragraph, sentence, or phrase, depending on the text. Each researcher determined the meaning units for half (two transcripts) of the 20 percent subset of transcripts. Then both researchers coded each meaning unit of all four transcripts independently. They compared coding and, after discussion, determined the interrater reliability for their coding using a simple percent agreement calculation, which resulted in 85 percent agreement. This level of agreement is sufficient to establish interrater reliability.

After 20 percent of the transcripts were coded by both researchers, the rest were coded by the primary researcher to establish trends. Within a single transcript, a code was counted only once for every one to three times it was mentioned; this reduced inflation of a code count when a code was mentioned various times by the same participant, but still accounted for special emphasis of a code by a participant. For example, if the researcher coded a particular concept four times for a single participant, that code would be counted twice; if it was coded twice, it would be counted once.

In addition to coding the transcripts to look for themes, the researchers also documented demographic information and simple yes or no questions to provide context for the participants' education and teaching experience. This quantitative data serves as a supplement to the 
exploration of trends through the coding process, improving the reliability and richness of the data used for the study, and increasing the researchers' confidence in the themes discovered.

\section{Results}

The 21 participants of the study came from a variety of institutions, including public, private, community college, and regional or satellite institutions. The participants were working in 18 different states, and their institutions' student populations ranged from 1,700 to 30,000. The majority of participants had been in their current position for one to six years, but their level of experience varied as well.
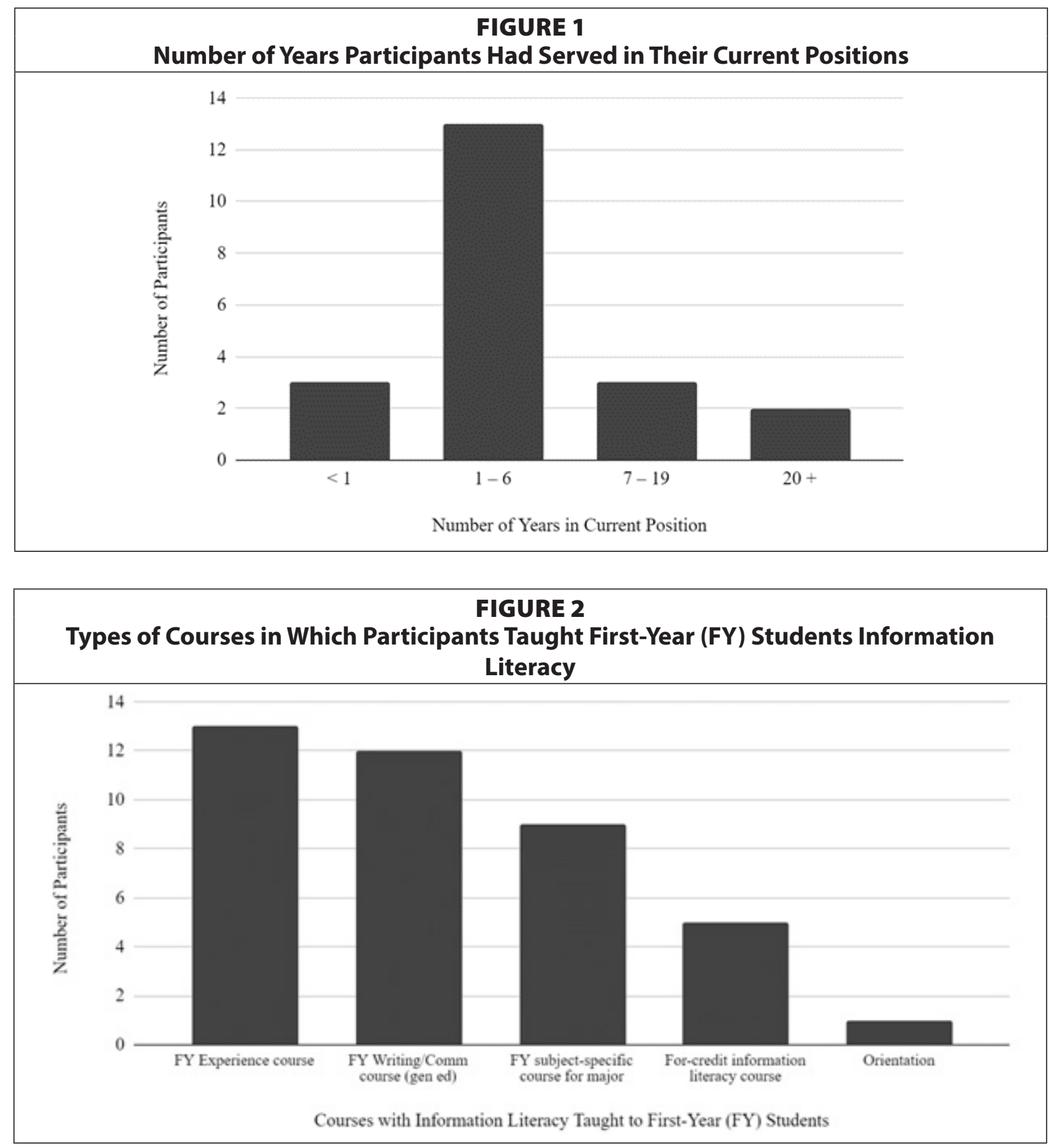
Most participants either described themselves as instruction librarians $(62 \%)$ or subject librarians who spent considerable time working with first-year students $(43 \%)$. The capacity in which participants taught first-year students generally consisted of instruction for a firstyear experience course, a first-year composition or communication course, a subject-specific course with mostly first-year students, or a credit-bearing information literacy course.

When asked about their training in instruction and educational theory, most participants cited on-the-job experience $(60 \%)$ or professional development $(60 \%)$ as the primary source of their instruction knowledge. None of the participants credited a required course in teaching during their MLIS/equivalent degree, but eight (40\%) did take an optional instruction course. Five participants also had a bachelor's degree, minor, or certification in education.

\section{Themes}

In the course of developing codes and thoroughly examining all of the transcripts, the researchers uncovered common themes throughout the participant responses. The themes generally fell into three main categories: Critical Thinking Characteristics (Skills and Dispositions), Critical Thinking vs. Information Literacy, and Critical Thinking Teaching and Assessment Strategies. Each theme and its associated codes are described below.

\section{Theme 1: Critical Thinking Characteristics (Skills and Dispositions)}

Participants were asked to describe critical thinking in several interview questions, revealing the skills and dispositions they associated most closely with critical thinking. Evaluating sources, considering multiple perspectives, and questioning or being skeptical were mentioned

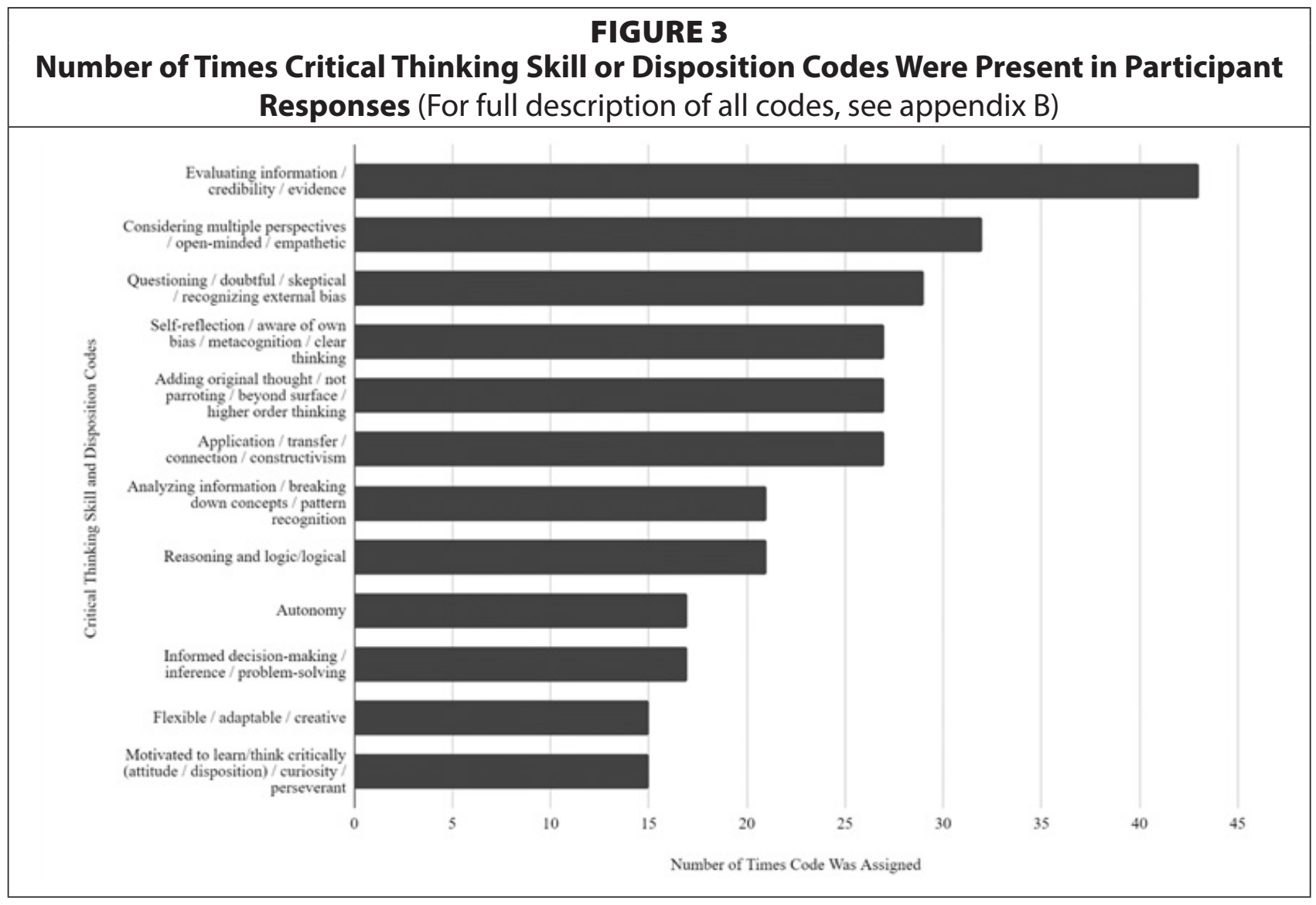


most often. Many librarians in the study described critical thinking as involving a sense of skepticism or a questioning attitude. One participant, Sofia, emphasized critical thinking as "the habit of mind that you almost do without thinking that leads you to question and reflect on information you encounter ... The earlier you can get this into students to think, to question, to reflect, the better." Zoe, another participant, saw critical thinking as "asking questions. Wanting to dig deeper into something, an idea, and wanting to know more."

Others were worried that too much skepticism could leave students feeling cynical and distrusting of everything. Kailani said, "Especially in this day and age, you feel like you have to be extra skeptical ... probably not the right word. Cautious. ... I'm starting to encounter students that are too skeptical; they don't believe anything." Edith and Sam, respectively, reiterated that successful critical thinking instruction is a balance: "[We should be] teaching them that healthy skepticism should take place. It's a medium between not believing everything you see and hear, but also not being completely pessimistic about everything you see and hear," and "Essentially, [critical thinking] is informed skepticism. It's not cynical skepticism, but an evidence-based approach."

In addition to identifying skepticism and questioning as important skills, librarians also noted that an openness to new ideas and alternative perspectives is an important component of critical thinking. Elif described critical thinking as "looking at something from multiple perspectives ... for arriving at a conclusion. And I think part of that is, hopefully you're getting closer to the truth, but you're also not holding too tightly to it." Edith emphasized the importance of "having an open mind, even if you already have a strong feeling about something," and Mustafa stressed "being open to enter[ing] into a quality dialogue with other people with competing viewpoints." Tying the concept to creative thinking, Jacinta emphasized that "to me, critical thinking is thinking outside the box. You can have an idea, and you can have an answer to a question, but if you can't think outside of what's in front of you, then you're not thinking critically about it."

Original thought, thinking deeply, self-reflection, and application/transfer of skills were critical thinking skills also mentioned often. A number of librarians interviewed reported that an indicator of critical thinking is when students are "not just parroting backwards what they've heard" (Sofia), or that, for students, "the first domain is original thought versus repetition" (Carol). Participants described critical thinkers as individuals who pause, take time to think deeply about information or a decision, and look beyond the surface of what they've been presented. Maria addressed the example of website URLs:

Something that I see a lot is, [the students will] say, "If it's a .edu, .org, or .gov website then it's more credible than a .com." And saying, "Okay, that is something that is unfortunately not necessarily true. It would be nice if we could use those criteria absolutely, but if you think about it, even the website we're using now, Libguides.com, is a .com website." I also use my-own-name.org and will edit it in class off of something we've said or talked about to show that I can make it say anything I want.

Some participants linked this deep-thinking to a student's sense of autonomy and ability to evaluate sources beyond an initial, gut reaction. Shanice emphasizes to her students that "you don't evaluate things, information, based on your gut or your opinion or what you've been told by your parents." Flora also highlights the importance of independent thinking: “To 
me critical thinking involves the ability to move beyond just looking at a set of instructions and more the ability to take an idea and kind of run with it without needing to be spoon-fed instructions." For Lena, evidence of deep thought is a strong indicator of critical thinking: "I would rather have a student give me a wrong answer but be able to demonstrate how they may have reached that wrong answer than have a student who just happens to have the right answer, but they have no idea why that's the right answer."

Another important critical thinking skill mentioned frequently was the ability to selfreflect and use metacognition to improve one's own thinking. Mustafa said he characterized critical thinking as "knowing that you always have to be willing to change your mind on something, that your opinions can change and, depending on what we're talking about, should change." Danielle described it as: "at its core, the ability to reflect on a deep level." Several participants mentioned critical thinking in terms of metacognition, or the ability to recognize and regulate one's own thinking. For example, Maria advised that first-year students "should be encouraged to explicitly reflect on their own thinking and their own reasoning. Which is something that they might have to be told to do. So, engage in metacognition: think about your thinking."

An important part of self-reflection is the ability to recognize one's own biases. Elif described critical thinking as "checking to see if you have any biases or prejudices that are clouding your thinking." Maria builds on this idea by recognizing that students "need to be encouraged not to close off their thinking based on their pre-existing beliefs, biases, judgments." Mustafa encourages students to "purposely seek out information that challenges the thinking process" and "[hit] that cognitive dissonance head-on with the express purpose of trying to resolve it through being more informed as opposed to just trying to avoid it." These understandings of self-reflection go beyond just taking time to consider thought processes, to actively guarding against opinions and ideas that are not well-founded.

Finally, many participants saw the ability to take skills learned in one realm and apply them to new contexts as an important critical thinking skill. Li defined critical thinking as "the ability to take information and apply it in new ways. Application without prompting is always really impressive to me and I think that is ... critical thinking when that happens." For many participants, transfer-of-skills also involved building on current knowledge based on new information. For example, Carol looked for students to "take their knowledge that they know and synthesize the situation with that knowledge and then add to that situation new knowledge. Instead of just repeating or regurgitating something." Similarly, Kailani described critical thinking as "not just a passive activity, [but] an active activity, which asks an individual to take information and assess the quality and use that to build knowledge."

\section{Theme 2: Critical Thinking vs. Information Literacy}

Participants were all asked to describe the relationship between critical thinking and information literacy. Interestingly, some participants claimed these two concepts were identical. For example, when asked about the relationship between critical thinking and information literacy, Nikita said, "Oh my gosh, I think they're related in every single way," and Lena said, "To me, they're so related that they're nearly interchangeable." Most others described information literacy as completely consisting of critical thinking skills, even if some critical thinking skills do not overlap with information literacy. Anton pointed out that critical thinking is a term that is often more quickly recognized and widely respected by others than information 


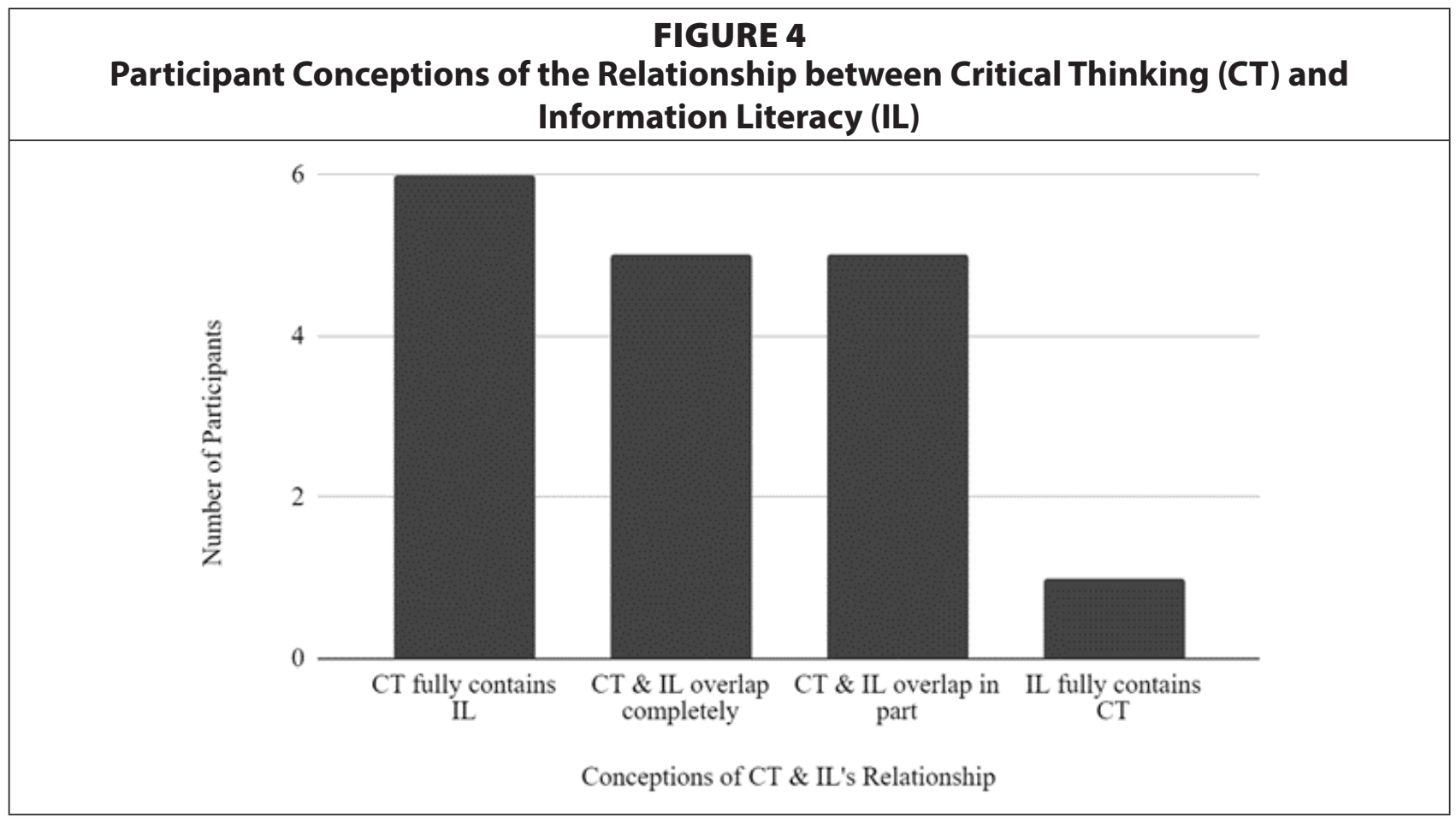

literacy. He posits that "librarians would get more buy-in by referring to critical thinking rather than the language of the [ACRL] Framework." These responses provide evidence that librarians often see the relationship between critical thinking and information literacy as so close as to be transposable.

However, one related issue that emerged from the interviews was the role that basic research skills play in librarian-led information literacy sessions and whether these can be considered information literacy skills, even though they arguably do not require critical thinking. Shanice acknowledged the difference between these sets of skills when she said, "I kind of distinguish library research skills from information literacy in my instruction. I teach both of those things." Hitting upon the root of the question, Kavya asked, "If we teach [students] how to think and how to work on their research question and think about all different kinds of sources, but they still can't find a book, have we ultimately failed them?" The role that basic research skills that do not require critical thinking play in information literacy instruction (and their role in the Framework as opposed to the Standards) requires further investigation.

Some participants described the relationship between critical thinking and information literacy one way but later contradicted themselves or otherwise described it inconsistently throughout the interview. Danielle described the debate that ensued in her own library when she brought the question of the relationship between the two terms to her colleagues:

I asked my colleagues... and we had a huge debate. There's definitely no consensus in my unit. So, initially, my thinking was that critical thinking was this larger umbrella term and that information literacy kind of connected underneath that. But I mentioned that to my colleagues and ... they were like, "No, no, no." ... Some of my colleagues were saying that they saw [critical thinking and information literacy] as completely separate ... I don't know. We had a pretty heavy debate. 
Based on our research, there is still no consensus among practicing instruction librarians about the relationship between critical thinking and information literacy. More research that explores the terms' relationship in practice is needed.

\section{Theme 3: Critical Thinking Teaching and Assessment Strategies}

Participants were asked to describe how they teach and assess critical thinking in library instruction. The most common teaching strategies mentioned were active learning, questioning/ Socratic method strategies, and asking students to articulate their thought processes. Some active learning strategies used by participants included group work, evaluating given sources, online polling software, concept mapping, and peer learning. Using questioning and discussion in the classroom were especially popular techniques, a conclusion exemplified by a quote from Tara: "I don't think there are ever too many times when you can ask why." Similarly, Carol calls herself a "question guider."

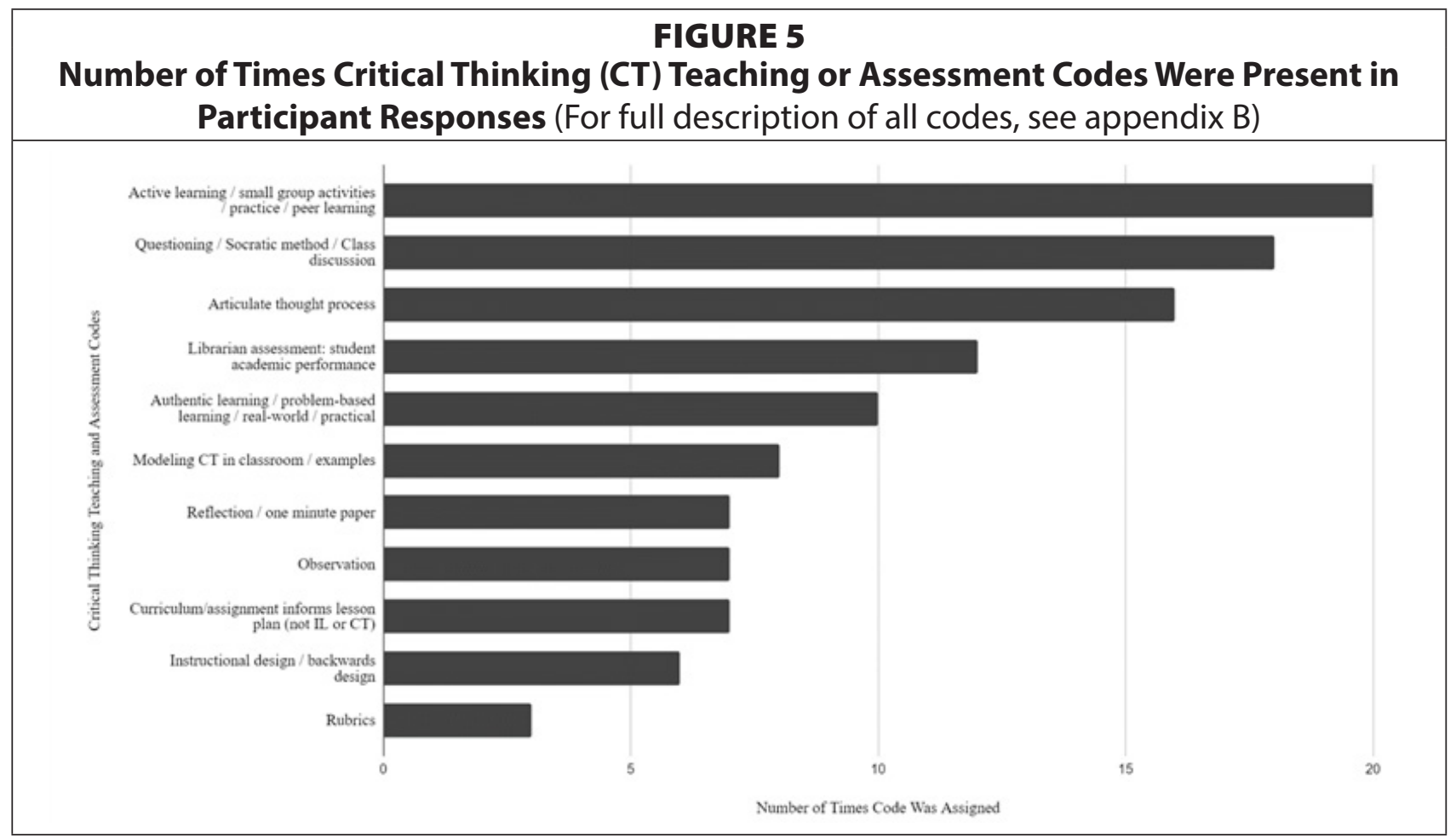

Participants were asked to describe how they would assess both a student's critical thinking skills and a teaching librarian's critical thinking instruction. In both cases, participants admitted that such an endeavor would be challenging and that significant development of students' critical thinking skills may not be possible from a one-shot session. Two strategies mentioned frequently for assessing a librarian's teaching were to have the librarian's instruction observed and to look at student work for evidence of critical thinking. However, in the latter case, determining the role of the librarian in fostering that critical thinking would be next to impossible. Most participants viewed critical thinking from library instruction as a long-term goal that may not be assessable in most individual library sessions.

Overall, many participants expressed frustration about a lack of time to teach critical thinking, as well as limitations placed on them by faculty priorities for library instruction 
sessions. Some also noted a discomfort with commonly used, simplistic tools for teaching critical thinking skills, such as the use of checklists like the CRAAP test. A dislike of the term "standards" also pervaded the responses. According to Sam, "I would say it's not important for [the students] to have checklists or standards, because they're too prescriptive. Instead, students should be asking questions."

\section{Other Topics That Emerged During the Interviews}

Some additional ideas emerged from the interviews that did not directly describe skills or dispositions of critical thinking, nor methods for teaching and assessing it. The concept of news literacy arose a number of times, perhaps not surprisingly, given current events, and several participants directly invoked the ACRL Framework as well.

Because this study focused on first-year students, many participants noted the cognitive development of the typical first-year student and the fact that many students had not matured beyond black-and-white thinking or the idea that all opinions are equally valid..$^{30}$ Maria asserted that first-year students often have a low tolerance for ambiguity and need to "be willing to engage with that messiness." Many also argued that high schools often do not prepare students to think critically, and they especially disparaged standardized testing. Damion said, "Some of [the students] come from schools where it was all 'teach to the test" and they never have to write a paper in high school, which infuriates me." Carol observed, "I think there's a lot of basics that students don't come to us with, so to jump to more abstract critical thinking can be more difficult." Anton suggested that, often, the role of college is to help students mature: "A purpose of higher ed. and information literacy is to usher in adulthood [for students]." Most participants stressed that the varying maturity levels with which students approach research in their first year is not their fault and that, throughout the course of their post-secondary education, students will acquire a more complex epistemology.

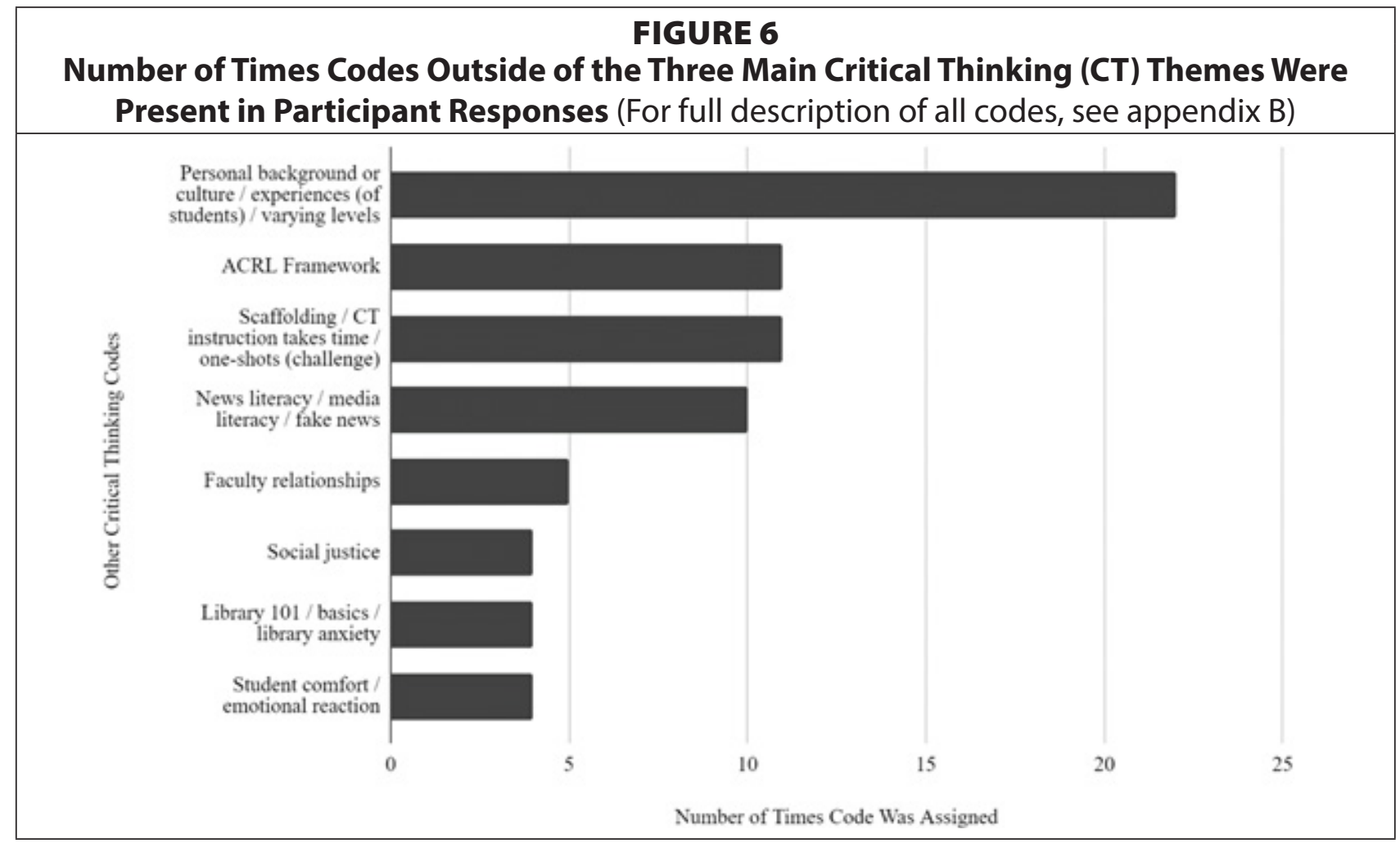


In general, participants noted that first-year students are starting their college career with a range of skills and facing challenges that previous generations did not face. Kavya observed, "I think they're coming out [of high school] with more skills, but they also have more information to apply those skills to, which creates an even larger challenge than maybe my own experience." Students also have a variety of experiences exercising critical thinking skills while growing up, and, as Rhonda emphasized, they may find their beliefs challenged in a higher education environment: "One good thing about college is sometimes, earlier, students aren't forced to [think critically], so when you come to college, things that you believe in that you might have been taught as a kid or that you believe really strongly [are] sometimes opposed, so that forces you to think about it - do I actually still believe it? And think critically." Several participants also noted that first-generation students, students for whom English is a second language, and nontraditional students all may bring unique challenges and perspectives to the classroom when it comes to critical thinking instruction. There was a consensus among participants that first-year students have varying competence in using critical thinking skills but that all have the potential to improve during the course of their academic careers.

Some participants noted that critical thinking extends beyond information literacy skills and wondered who else is responsible, in a formal capacity, to ensure that students develop critical thinking skills. A sense that librarians do not have the time to fully address critical thinking in one-shot sessions underscored a concern that librarians should not be the only ones teaching critical thinking to first-year students. Elif suggested that librarians may also lack the expertise to teach some critical thinking skills: "When you get to that level [of critical thinking instruction], there are other people that are better equipped ... So probably the faculty member would agree with me that I'm not the best person to do that, but I would agree with them that I'm not the best person to do that. ... So the question is: Is it me, or is it them [responsible for teaching critical thinking]? I think it's both." Like information literacy, critical thinking may be a concept that is valued by our institutions but needs to be more deliberately incorporated into the curriculum (including in library instruction) to be effectively fostered in our students.

Finally, when asked about information literacy instruction training and, in particular, teaching critical thinking skills, many participants expressed frustration at not having received formal training opportunities in library school. For example, Edith said, "I just want to be on record saying that this is a fault of many library schools that do not train library students to be educators in this way in terms of showing students how to critically think about information or just in general information literacy and teaching it." Carol echoed Edith by saying, "I would love to see more of the [MLIS] graduate programs give some pedagogy [training] as they provide people with their advanced degrees." In general, those with an education degree or certification were more comfortable talking about critical thinking instruction. More training and professional development opportunities specifically focusing on teaching critical thinking skills in information literacy instruction could help.

\section{Implications and Conclusions}

Conducting this study was illuminating in many ways, one of which is that it gave the researchers an opportunity to witness librarians working through difficult conceptual questions and issues. The subject of critical thinking is mostly absent from the ACRL Framework (at least explicitly), and, clearly, more discussion about what role critical thinking plays in library 
instruction is necessary. It was particularly instructive to hear librarians describe information literacy and critical thinking as completely overlapping. While information literacy and critical thinking are not necessarily the same, they were perceived by the interviewed instruction librarians to be at least highly related. The close relationship between information literacy and critical thinking provides librarians with opportunities to improve their instruction by reframing their faculty communication in terms of critical thinking, examining the relationship between other values-driven teaching approaches (such as critical librarianship) and critical thinking instruction, and using critical thinking as a guide in addressing misinformation and other information-related real-world problems.

Developing students' information literacy skills is a primary goal of academic librarians, so if that endeavor necessarily entails developing critical thinking skills, finding ways to integrate critical thinking into library instruction should be a high priority. However, the study participants pointed out that it is challenging to gain the time and freedom to teach students critical thinking skills, which are difficult to learn and require repeated practice. Often, librarians are limited in their ability to choose the content of library instruction, influence the assignments that students are given, and engage with students for sufficient time to impart instruction in critical thinking. The literature suggests that flipped classroom approaches, cooperative assignment planning with faculty, and having discussions with faculty can help address this problem. ${ }^{31}$

However, another potential approach would be to make the relationship between information literacy and critical thinking skills (or, simply, the work of instruction librarians) more transparent to faculty. The term "critical thinking" is likely more familiar to them, and institutions are often quick to point out that students need critical thinking skills, even while there is no formal place for critical thinking in the curriculum. For example, many academic programs adhere to accrediting bodies that emphasize the importance of enhancing students' critical thinking skills but not necessarily information literacy skills. Describing library instruction as a source for critical thinking training could raise its profile. There is also an enormous body of research both describing critical thinking instructional techniques and proclaiming their effectiveness. Library school training in teaching critical thinking skills and framing library instruction in terms of critical thinking may help.

In recent years, teaching librarians have been more firmly embracing their identities as instructors. ${ }^{32}$ Perhaps an extension of this transformation should involve reframing library instruction as critical thinking instruction when possible. For instruction librarians, teaching critical thinking skills, as opposed to "point and click" skills, has the potential to be more impactful for students, as well as more meaningful to the librarian. While the connection was not made explicit by study participants, recent scholars have redefined critical thinking in terms of critical pedagogy, an important theory underlying social justice efforts in academia. ${ }^{33}$ Reframing library instruction in terms of critical thinking can therefore support librarians' goals of promoting social justice as well.

These interviews reveal that librarians are often eager to discuss critical thinking's role in information literacy instruction, as well as the value of such instruction for solving realworld problems. Many drew connections between critical thinking skills and the application of these skills to important societal challenges, such as the spread of misinformation or the struggle for social justice. More discussions about critical thinking and information literacy, as well as the formalization of the relationship between the two, could help librarians clarify 
their role in combating misinformation, hyperpartisan division, cognitive bias, and other causes of societal problems.

Presented here are several recommendations, based on analysis of the participants' responses, for academic librarians who teach first-year students:

- Use information literacy instruction to help first-year students balance questioning and skepticism skills with the habits of being open-minded and considering alternative perspectives.

- Help first-year students think more deeply and understand their own thinking processes by encouraging metacognition.

- Discuss the relationship between critical thinking and information literacy with colleagues. It may be surprising to learn how differently others imagine the relationship, despite the common assumption that everyone understands both concepts and their role.

- Use active learning techniques, especially questioning strategies, to engage first-year students in critical thinking.

- Recognize that first-year students may bring a wide variety of high school, upbringing, and other relevant experiences to information literacy instruction. Students will have diverse skill and tolerance levels for critical thinking instruction, a fact that is at least somewhat influenced by their maturity level.

- Manage faculty expectations about what critical thinking skills students can reasonably master in one-shot information literacy sessions.

Despite the potential for takeaways from this study's conclusions, there are several limitations to the applicability of the study. The librarian participants may have strong inclinations toward critical thinking and information literacy that prompted them to initially volunteer, so their responses may not be an accurate representation of academic librarians who teach information literacy to first-year students. Further, this study used grounded theory to allow the data to speak for themselves and allow themes to emerge during the coding phase. This scope of methodology requires flexibility and does not lend itself well to reproducibility. Finally, the prescribed questions created by the researchers may have been confusing or too limiting for participants to fully address the issues that were salient to the study's objectives.

The goals of this research were to explore librarians' attitudes toward teaching critical thinking to first-year students, define the perceived relationship between critical thinking and information literacy, and determine how academic librarians teach critical thinking in information literacy sessions. Through a thorough examination of transcripts, the researchers discovered common library instruction methods for teaching critical thinking, determined how the participants perceive the relationship between critical thinking and information literacy, and identified areas for growth in library instruction programs hoping to collaborate with faculty in promoting critical thinking. The results should help academic librarians who teach first-year students better integrate critical thinking into their instruction and identify areas of study that require more research. 


\section{APPENDIX A \\ Interview Protocol}

Interviewee Pseudonym:

Interviewer:

I. Interview Introduction

Hello, my name is Thank you so much for conducting this interview with me today. Before we get started, I'm going to tell you a little bit about our study and cover some housekeeping details.

To help us with our notes, I am going to audio-record this interview. Just so you know, only the researchers will have access to these recordings. For confidentiality, we're going to use study codes and pseudonyms on transcripts instead of recording identifying information. The recordings will be destroyed after they are transcribed and the transcripts will be destroyed after three years. You also submitted a signed form to us, which describes how we will keep the content of these interviews confidential. Do you have any questions about that form or the audio-recording of this interview?

Please let me know if you would like to stop the interview or stop recording at any time. You may also stop me at any time to ask questions. This interview is scheduled to last no longer than an hour. During this time, I'm going to ask you some questions, and I encourage you to give as complete of an answer as you would like. As was mentioned in the form you signed, this study seeks to explore the attitudes and understanding of academic librarians when it comes to critical thinking. We are especially interested in understanding the experience of librarians who teach first-year students. As you answer the questions we will discuss today, please limit your answers to your experience teaching first-year students as much as possible. Do you have any questions before we begin?

II. Interviewee Background

a. How long have you been in your current position?

b. Could you describe the teaching responsibilities you have in your current position, especially as they relate to first-year students?

c. What training or education do you have in education or educational theory?

III. Critical Thinking Foundations

a. In your view, do you think of knowledge, truth, and sound judgment as:

i. $\quad$ Not fundamentally a matter of my own personal preference or subjective taste, or

ii. Fundamentally, a matter of my own personal preference or subjective taste

b. Would you explain to me your concept of critical thinking? If you like, you can begin by completing the sentence, "To me, critical thinking is

c. Could you give me an example of how critical thinking is useful outside the classroom that illustrates your concept of it? (in other words, as a consumer, parent, citizen, in a relationship, or other role)

d. What intellectual standards would you use to distinguish whether or not thinking 
processes are being done critically or not?

e. Does your conception of critical thinking involve any particular traits of mind?

f. My concept of critical thinking is largely:

i. Intuitive in my thinking, or

ii. Explicit in my thinking

g. My concept of critical thinking is largely

i. A product of my own thinking

ii. A product of one or more particular theories of critical thinking to which I explicitly subscribe

h. How do you think critical thinking and information literacy are related?

IV. Critical Thinking in Library Instruction

a. How important is critical thinking to your instructional objectives when teaching first-year students?

i. Of little or small importance

ii. Of secondary importance

iii. Of primary importance

b. In your view, how important is it for first-year students to acquire sound intellectual criteria or standards to use in the assessment of their own thinking and the thinking of others?

i. Of little or small importance

ii. Of secondary importance

iii. Of primary importance

c. Is there anything you do on a regular basis in your teaching of first-year students that you believe fosters critical thinking?

d. Do you have any methods that you find particularly effective in teaching first-year students to think critically about information literacy?

e. Some librarians feel they have too much content to cover to have much time left for fostering critical thinking in library instruction sessions. What is your view of this position?

f. What particular critical thinking skills do you believe are most important for firstyear students to develop?

g. If you had the task of assessing the extent to which a librarian was or was not fostering critical thinking through his/her instruction, how would you go about making that assessment?

V. Critical Thinking and Students

a. Do you feel that first-year students generally come to your classes with well-developed intellectual standards or criteria to use in assessing thinking?

i. In general, yes, or

ii. In general, no

b. What qualities do you look for in first-year students' reasoning that tell you whether or not they are thinking critically?

c. If a first-year student asked you what criteria she should use to decide whether to accept or reject a position someone is defending, what would you tell her?

Before we conclude the interview, is there anything else you would like to share about your conception of critical thinking or first-year students' experience learning to be critical thinkers? 


\section{APPENDIX B \\ Teaching Critical Thinking to First-Year Students through Information Literacy Instruction: Codebook}

\begin{tabular}{|c|c|}
\hline Code & Definition \\
\hline $\begin{array}{l}\text { Questioning / doubtful / skeptical / } \\
\text { recognizing external bias }\end{array}$ & $\begin{array}{l}\text { An attitude of having doubts or reservations; needing } \\
\text { more evidence or having additional questions }\end{array}$ \\
\hline $\begin{array}{l}\text { Self-reflection / aware of own bias / } \\
\text { metacognition / clear thinking }\end{array}$ & $\begin{array}{l}\text { A tendency to think about one's own thinking process and } \\
\text { decision-making }\end{array}$ \\
\hline $\begin{array}{l}\text { Considering multiple perspectives / open- } \\
\text { minded / empathetic }\end{array}$ & $\begin{array}{l}\text { A tendency to consider alternative ideas or outside } \\
\text { viewpoints and change one's opinion or knowledge based } \\
\text { on reliable new information }\end{array}$ \\
\hline Flexible / adaptable / creative & $\begin{array}{l}\text { The ability to adapt to new and unfamiliar scenarios or } \\
\text { information, and/or the ability to devise or construct new, } \\
\text { effective approaches or products }\end{array}$ \\
\hline $\begin{array}{l}\text { Analyzing information / breaking down } \\
\text { concepts / pattern recognition }\end{array}$ & $\begin{array}{l}\text { The ability to recognize sequences or relationships in } \\
\text { information; to organize or conceptualize information in } \\
\text { useful ways }\end{array}$ \\
\hline $\begin{array}{l}\text { Evaluating information / credibility / } \\
\text { evidence }\end{array}$ & $\begin{array}{l}\text { The ability to use appropriate, evidence-based, and/or } \\
\text { rational criteria to evaluate information }\end{array}$ \\
\hline Autonomy & $\begin{array}{l}\text { The ability to perform higher-order thinking without } \\
\text { direction or instruction from an adult or other authority }\end{array}$ \\
\hline $\begin{array}{l}\text { Adding original thought / not parroting } \\
\text { / beyond surface / higher level/order } \\
\text { thinking / slow thinking }\end{array}$ & $\begin{array}{l}\text { The ability to synthesize information with new thoughts or } \\
\text { ideas, coming to new and valuable conclusions }\end{array}$ \\
\hline $\begin{array}{l}\text { Motivated to learn/think critically (attitude } \\
\text { / disposition) / curiosity / perseverant }\end{array}$ & $\begin{array}{l}\text { The tendency to be motivated to think critically and use } \\
\text { the skills described in the other codes }\end{array}$ \\
\hline Reasoning and logic/logical & $\begin{array}{l}\text { The ability to use inductive and deductive reasoning } \\
\text { and logic, as well as the ability to identify poor logic or } \\
\text { reasoning }\end{array}$ \\
\hline $\begin{array}{l}\text { Application / transfer / connection / } \\
\text { constructivism }\end{array}$ & $\begin{array}{l}\text { Using critical thinking skills appropriately in new contexts; } \\
\text { applying critical thinking skills to previous knowledge/ } \\
\text { skills }\end{array}$ \\
\hline $\begin{array}{l}\text { Informed decision-making / inference / } \\
\text { problem-solving }\end{array}$ & $\begin{array}{l}\text { Using critical thinking skills to make decisions, solve } \\
\text { problems, or make inferences based on evidence and/or } \\
\text { reasoning }\end{array}$ \\
\hline $\begin{array}{l}\text { Questioning / Socratic method / Class } \\
\text { discussion }\end{array}$ & $\begin{array}{l}\text { Asking students questions or having students develop } \\
\text { questions; discussing issues as a class }\end{array}$ \\
\hline $\begin{array}{l}\text { Active learning / small group activities / } \\
\text { entrance/exit activity / think-pair-share / } \\
\text { practice / peer learning / brainstorming }\end{array}$ & $\begin{array}{l}\text { Any activities that require students to actively engage with } \\
\text { the class content }\end{array}$ \\
\hline Reflection / one-minute paper & $\begin{array}{l}\text { Activities that ask students to reflect on the content of the } \\
\text { instruction, how it was delivered, or their own thinking }\end{array}$ \\
\hline
\end{tabular}




\begin{tabular}{|c|c|}
\hline $\begin{array}{l}\text { Authentic learning / problem-based } \\
\text { learning / real-world / practical }\end{array}$ & $\begin{array}{l}\text { Learning activities that draw on examples from students' } \\
\text { own lives, current events, or difficult issues faced by many } \\
\text { in society }\end{array}$ \\
\hline Pre-/post-test & Using a pre- and post-test to assess student learning \\
\hline $\begin{array}{l}\text { Personal background or culture / } \\
\text { experiences (of students) / varying levels }\end{array}$ & $\begin{array}{l}\text { The influence of students' cultural or experiential } \\
\text { background on their introduction to or abilities regarding } \\
\text { critical thinking skills }\end{array}$ \\
\hline News literacy / media literacy / fake news & $\begin{array}{l}\text { Competence and skills when using news or other online } \\
\text { sources; only used when specifically mentioned }\end{array}$ \\
\hline $\begin{array}{l}\text { Scaffolding / CT instruction takes time / } \\
\text { one-shots (challenge) }\end{array}$ & $\begin{array}{l}\text { The need for time and incremental instruction to } \\
\text { effectively teach critical thinking }\end{array}$ \\
\hline Social justice & $\begin{array}{l}\text { Concerns about just treatment of all members of society as } \\
\text { it relates to critical thinking }\end{array}$ \\
\hline ACRL Framework & $\begin{array}{l}\text { References to the ACRL Framework; only used when } \\
\text { specifically mentioned }\end{array}$ \\
\hline Library 101 / basics / library anxiety & $\begin{array}{l}\text { Teaching students the basics about using the library, } \\
\text { including addressing their anxiety about using it }\end{array}$ \\
\hline Modeling CT in classroom / examples & $\begin{array}{l}\text { Demonstrating critical thinking by modeling it in the } \\
\text { classroom and/or showing examples of good critical } \\
\text { thinking }\end{array}$ \\
\hline Instructional design / backwards design & $\begin{array}{l}\text { Deliberate approaches to designing instruction using } \\
\text { pedagogy and instructional theory }\end{array}$ \\
\hline Annotated bibliography & Mention of annotated bibliography assignment \\
\hline $\begin{array}{l}\text { Articulate thought process } \\
\text { (communication) }\end{array}$ & $\begin{array}{l}\text { Asking students to communicate their thought processes, } \\
\text { either verbally or in written form }\end{array}$ \\
\hline Observation & Observing other librarians to assess their instruction \\
\hline Student comfort / emotional reaction & $\begin{array}{l}\text { Concerns about students' emotional reaction to critical } \\
\text { thinking instruction, or their general sense of ease } \\
\text { employing critical thinking skills in the classroom }\end{array}$ \\
\hline Rubrics & Use of rubrics as an assessment tool \\
\hline $\begin{array}{l}\text { Librarian assessment: student academic } \\
\text { performance }\end{array}$ & $\begin{array}{l}\text { Assessing librarian instruction of critical thinking by } \\
\text { assessing or examining student work after a library session }\end{array}$ \\
\hline $\begin{array}{l}\text { Curriculum/assignment informs lesson } \\
\text { plan (not IL or CT) }\end{array}$ & $\begin{array}{l}\text { Attitude that the professor, assignment, or curriculum is } \\
\text { the main driver for librarian instruction, not a focus on } \\
\text { critical thinking or information literacy }\end{array}$ \\
\hline Faculty relationships & $\begin{array}{l}\text { Mention of the impact of faculty relationships on library } \\
\text { instruction of critical thinking }\end{array}$ \\
\hline None & None of the codes apply \\
\hline
\end{tabular}

\section{Notes}

1. Association of College \& Research Libraries, "ACRL Framework for Information Literacy in Higher Education" (2016), www.ala.org/acrl/standards/ilframework.

2. Karen Forbes, "Exploring First Year Undergraduate Students' Conceptualizations of Critical Thinking Skills," International Journal of Teaching and Learning in Higher Education 30, no. 3 (January 1, 2018): 433-42; Thomas F. Nelson Laird et al., "Deeply Affecting First-Year Students' Thinking: Deep Approaches to Learning and Three 
Dimensions of Cognitive Development," Journal of Higher Education 85, no. 3 (2014): 402-32, https://doi.org/10.1353/ jhe.2014.0017; Theda Thomas, "Developing First Year Students' Critical Thinking Skills," Asian Social Science 7, no. 4 (2011): 26-35, https://doi.org/10.5539/ass.v7n4p26.

3. Mandi Goodsett, "Determining the Extent to Which Information Literacy Online Learning Objects Follow Best Practices for Teaching and Assessing Critical Thinking" (Thesis, Cleveland State University, 2018.)

4. Goodsett, "Determining the Extent to Which Information Literacy Online Learning Objects Follow Best Practices for Teaching and Assessing Critical Thinking."

5. Richard W. Paul, Linda Elder, and Ted Bartell, "California Teacher Preparation for Instruction in Critical Thinking: Research Findings and Policy Recommendations" (1997), https://eric.ed.gov/?id=ED437379.

6. Robert H. Ennis, "Critical Thinking and Subject Specificity: Clarification and Needed Research," Educational Researcher 18, no. 3 (1989): 4-10, https://doi.org/10.2307/1174885.

7. Peter Facione, "Critical Thinking: A Statement of Expert Consensus for Purposes of Educational Assessment and Instruction (The Delphi Report)," 1990.

8. Gerald Nosich, Learning to Think Things Through: A Guide to Critical Thinking across the Curriculum (London, UK: Pearson, 2009).

9. John E. McPeck, Critical Thinking and Education (Milton Park, UK: Routledge, 2016).

10. Deanna Kuhn, "A Developmental Model of Critical Thinking," Educational Researcher 28, no. 2 (1999): 16-46, https://doi.org/10.2307/1177186.

11. Diane F. Halpern, "Teaching for Critical Thinking: Helping College Students Develop the Skills and Dispositions of a Critical Thinker," New Directions for Teaching and Learning 1999, no. 80 (1999): 69-74.

12. Patricia M. King and Karen Strohm Kitchener, "Reflective Judgment: Theory and Research on the Development of Epistemic Assumptions through Adulthood," Educational Psychologist 39, no. 1 (2004): 5-18.

13. B. Inhelder and J. Piaget, The Growth of Logical Thinking from Childhood to Adolescence (London, UK: Routledge and Kegan Paul, 1958); Kuhn, "A Developmental Model of Critical Thinking."

14. Goodsett, "Determining the Extent to Which Information Literacy Online Learning Objects Follow Best Practices for Teaching and Assessing Critical Thinking."

15. Emily R. Lai, “Critical Thinking: A Literature Review," Pearson's Research Reports 6 (2011): 40-41.

16. Sonia Bodi, "Critical Thinking and Bibliographic Instruction," Journal of Academic Librarianship 14, no. 3 (July 1988): 150; Craig Gibson, “Critical Thinking: Implications for Instruction," RQ 35, no. 1 (1995): 27-36.

17. Maryellen Allen, "Promoting Critical Thinking Skills in Online Information Literacy Instruction Using a Constructivist Approach," College $\mathcal{E}$ Undergraduate Libraries 15, no. 1/2 (2008): 21-38, https://doi. org/10.1080/10691310802176780; Gwendolyn J. Reece, "Critical Thinking and Cognitive Transfer: Implications for the Development of Online Information Literacy Tutorials," Research Strategies 20, no. 4 (January 2005): 482-93, https://doi.org/10.1016/j.resstr.2006.12.018; Randy Burke Hensley, "Curiosity and Creativity as Attributes of Information Literacy," Reference \& User Services Quarterly 44, no. 1 (2004): 31-36, http://search.ebscohost.com. proxy.ulib.csuohio.edu:2050/login.aspx?direct=true\&db=eft\&AN=502936891\&site=ehost-live; Cheryl LaGuardia, "Renegade Library Instruction," Library Journal 117, no. 16 (1992): 51, http://search.ebscohost.com.proxy.ulib. csuohio.edu:2050/login.aspx?direct=true\&db=aph\&AN=9211166759\&site=ehost-live.

18. Trudi E. Jacobson and Thomas P. Mackey, "Proposing a Metaliteracy Model to Redefine Information Literacy," Communications in Information Literacy 7, no. 2 (2013): 84-91; CILIP Information Literacy Group, CILIP Information Literacy Definition 2018, https://infolit.org.uk/ILdefinitionCILIP2018.pdf

19. Rebecca S. Albitz, "The What and Who of Information Literacy and Critical Thinking in Higher Education," portal: Libraries and the Academy 7, no. 1 (January 18, 2007): 97-109, https://doi.org/10.1353/pla.2007.0000; Mark Alfino et al., "Advancing Critical Thinking and Information Literacy Skills in First Year College Students," College \& Undergraduate Libraries 15, no. 1/2 (2008): 81-98.

20. Alice L. Daugherty and Michael F. Russo, "Reinforcing Critical Thinking and Information Literacy Skills through Assignment Design," Louisiana Libraries 72, no. 3 (2010): 26-29.

21. John M. Weiner, "Is There a Difference between Critical Thinking and Information Literacy? A Systematic Review 2000-2009," Journal of Information Literacy 5, no. 2 (December 2011): 81-92.

22. Dani Brecher and Kevin Michael Klipfel, "Education Training for Instruction Librarians: A Shared Perspective," Communications in Information Literacy 8, no. 1 (2014): 12.

23. Richard E. Mayer and Patricia A. Alexander, Handbook of Research on Learning and Instruction (Milton Park, UK:Taylor \& Francis, 2016).

24. Elizabeth Bleicher, "Teaching Critical University Studies: A First-Year Seminar to Cultivate Intentional Learners," Honors in Practice 16 (January 1, 2020): 93-126; Byron Brown, "The Rigor and Exorbitance of Reading: Teaching Critical Thinking in the Freshman Honors Seminar," Proceedings of the National Conference on Successful College Teaching (18th, Orlando, Florida, February 26-28, 1994); Forbes, "Exploring First Year Undergraduate Stu- 
dents' Conceptualizations of Critical Thinking Skills"; Patricia A. Ralston and Cathy L. Bays, "Critical Thinking Development in Undergraduate Engineering Students from Freshman through Senior Year: A 3-Cohort Longitudinal Study," American Journal of Engineering Education 6, no. 2 (December 1, 2015): 85-98; Elise D. Wallace and Renee N. Jefferson, "Developing Critical Thinking Skills for Information Seeking Success," New Review of Academic Librarianship 19, no. 3 (September 2013): 246-55, https://doi.org/10.1080/13614533.2013.802702.

25. Forbes, "Exploring First Year Undergraduate Students' Conceptualizations of Critical Thinking Skills."

26. Brown, "The Rigor and Exorbitance of Reading."

27. Richard W. Paul, Linda Elder, and Ted Bartell, "California Teacher Preparation for Instruction in Critical Thinking: Research Findings and Policy Recommendations" (1997), https://eric.ed.gov/?id=ED437379.

28. "ACR: Another Call Recorder by NLL APPS Official Website," https://nllapps.com/apps/acr/ [accessed 10 May 2020].

29. John L. Campbell et al., "Coding In-Depth Semistructured Interviews: Problems of Unitization and Intercoder Reliability and Agreement," Sociological Methods \& Research 42, no. 3 (2013): 294-320.

30. Kuhn, "A Developmental Model of Critical Thinking."

31. Carolyn Caffrey Gardner and Jamie White-Farnham, "'She Has a Vocabulary I Just Don't Have': Faculty Culture and Information Literacy Collaboration," Collaborative Librarianship 5, no. 4 (2013): 3; Gerardo GómezGarcía et al., "The Contribution of the Flipped Classroom Method to the Development of Information Literacy: A Systematic Review," Sustainability 12, no. 18 (2020): 7273, https://doi.org/10.3390/su12187273; Thomas P. Mackey and Trudi E. Jacobson, "Information Literacy: A Collaborative Endeavor," College Teaching 53, no. 4 (2005): 140-44; Rich McCue, "Does a Blended Learning, Flipped Classroom Pedagogy Help Information Literacy Students in the Long-term Adoption of Research Skills?" Law Library Resource Xchange (LLRX) (2014).

32. Rachael A. Lewitzky, "Educating, Learning, and Growing: A Review of the Teaching Role in Academic Librarianship," College \& Undergraduate Libraries 27, no. 1 (2020): 32-40; Scott Walter, "Librarians as Teachers: A Qualitative Inquiry into Professional Identity," College \& Research Libraries 69, no. 1 (2008): 51-71, http://search. ebscohost.com.proxy.ulib.csuohio.edu:2050/login.aspx?direct=true\&db=eft\&AN=502932777\&site=ehost-live; Emily Wheeler and Pamela McKinney, "Are Librarians Teachers? Investigating Academic Librarians' Perceptions of Their Own Teaching Roles," Journal of Information Literacy 9, no. 2 (2015): 111-28, https://doi.org/10.11645/9.2.1985.

33. The Palgrave Handbook of Critical Thinking in Higher Education, eds. Martin Davies and Ronald Barnett (New York, NY: Springer, 2015). 